\title{
Identification of a novel MENI gene mutation in Saudi Arabian patient with multiple endocrine
} \section{tumors}

\begin{abstract}
Objective: To describe the diagnosis of an index MEN1 case with a novel mutation.

Methods: We present the clinical, laboratory, exam, and imaging findings, along with a review of the literature.

Results: A 28-year-old Saudi male presenting with 2 years history of recurrent symptomatic hypoglycemia.

Further workup confirmed the clinical and biochemical diagnosis of consistent with MEN1 and genetic testing proved this to be a novel mutation in the gene.
\end{abstract}

Conclusion: This case describes a novel mutation in the MEN1 gene raises the discussion if there will ever be a genotype-phenotype association as in other MEN syndromes.

Keywords: patient, tumors, syndromes, MEN1, phenotypic, skin, hypoglycemia, insulin
Volume 6 Issue 3 - 2018

\author{
Hanan Alshammari,' Jamal Alsaeed, ${ }^{2}$ Walid \\ Dridi ${ }^{3}$ \\ 'King Fahad Specialist Hospital Dammam, Saudi Arabia \\ ${ }^{2}$ Adult Endocrine Consultant, King Fahad Specialist Hospital \\ Dammam, Saudi Arabia \\ ${ }^{3}$ Genetic Consultant, King Fahad Specialist Hospital Dammam, \\ Saudi Arabia
}

\begin{abstract}
Correspondence: Hanan Alshammari, King Fahad Specialist Hospital-Dammam, Saudi Arabia-Ammar Bin Thabit St, Al MuraikabatØ氏 AI Muraikabat, Dammam 32253, Saudi Arabia, Tel +966-504994I50, Email hanan.nashmi@gmail.com
\end{abstract}

Received: February 08, 2018| Published: June II, 2018

\section{Introduction}

MEN1 syndrome clinical symptomatology is extremely heterogeneous. This important heterogeneity can be explained, to some extent, by the 1300 mutations identified to date in the MEN1 gene $^{1}$ Genotype-phenotype correlation is quite complex. A family can share the same MEN1 gene mutation and have important discrepancies at the phenotypic level. ${ }^{2}$ This huge genotype-phenotype variability can affect also identical twins. ${ }^{3,4}$ MEN1 gene is located on 11q13 and defined as a tumor suppressor gene.

Our patient was diagnosed for a large insulinoma $5 \mathrm{~cm}$, asymptomatic hyperparathyroidism and found to have diffuse skin tags and acanthosis nigricans. Molecular MEN1 gene sequencing revealed, so far in our knowledge, new heterozygous variant c. $1049+2 \mathrm{~T}>\mathrm{A}$.

\section{Case report}

This is 25- year-old male, who was referred to the endocrine clinic in September 2015 with 2 years history of frequent and severe episodes of hypoglycemia. This was accompanied with history of with episodes of loss of consciousness, significant weight gain $(45 \mathrm{~kg})$ but no other complaints and insignificant past medical, surgical and family history.

Also, the patient noticed appearance of skin tags on his skin, especially over underarm and lower abdominal area, with darkening of skin color in similar skin tags distribution. No history of renal stones or bone fractures.

Physical examination: morbid obese, BMI 50, extensive acanthosis nigran over neck both sides, under arms, lower abdominal And diffuse skin tags in under arms, lower abdomen (Figure 1A \& B).

\section{Clinical course}

Patient has been admitted, he received intravenous fluid dextrose overcome the sever asymptomatic hypoglycemia. The biochemical diagnosis of insulinoma was secured followed by localization (Table $1)$.

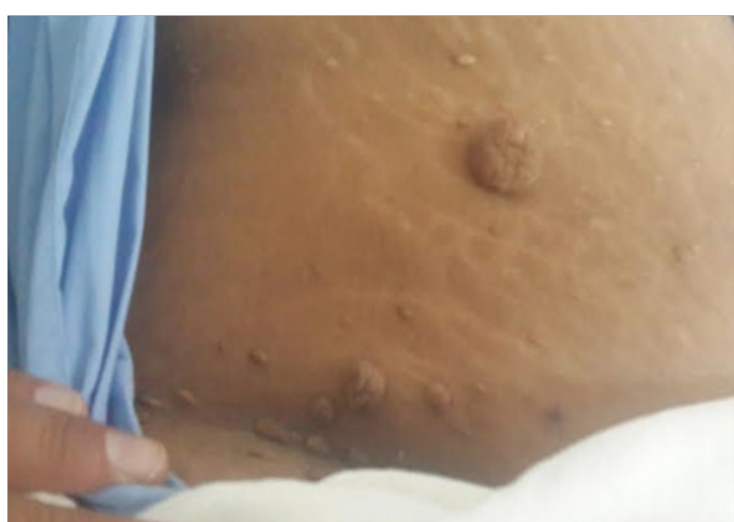

A

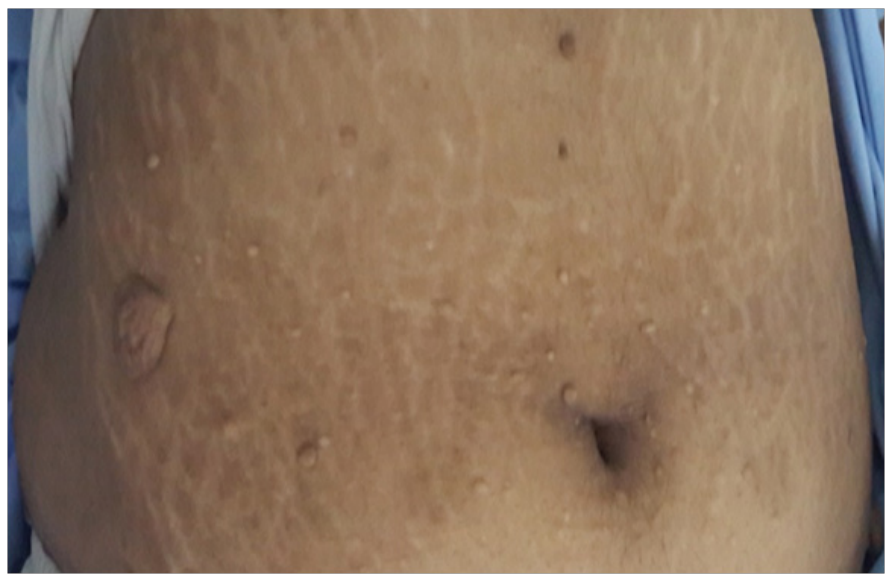

B

Figure IA \& B multiple skin tags over lower abdomen area 
Table I Labs results

\begin{tabular}{lll}
\hline Lab & Result & Reference range \\
\hline Fasting blood glucose & $36 \mathrm{mg} / \mathrm{dl}$ & $70-100 \mathrm{mg} / \mathrm{dl}$ \\
Insulin & $182.7 \mathrm{pmol} / \mathrm{L}$ & $43-193 \mathrm{pmol} / \mathrm{L}$ \\
C-peptide & $1578 \mathrm{pmol} / \mathrm{L}$ & $260-1390 \mathrm{pmol} / \mathrm{L}$ \\
Proinsulin, P & $100 \mathrm{pmol} / \mathrm{L}$ & $3-20 \mathrm{pmol} / \mathrm{L}$ \\
Hypoglycemic agent & Negative & \\
screen(sulfonylurea) & $3.60 \%$ & \\
Hbalc & $0.9 \mathrm{mmol} / \mathrm{L}$ & $0.8-1.5 \mathrm{mmol} / \mathrm{L}$ \\
Phosphor & $2.74 \mathrm{mmol} / \mathrm{L}$ & $2.20-2.60 \mathrm{mmol} / \mathrm{L}$ \\
Corrected calcium & $7.8 \mathrm{nmol} / \mathrm{L}$ & $30-100 \mathrm{nmol} / \mathrm{L}$ \\
25 vitamin D & $262 \mathrm{pg} / \mathrm{ml}$ & $5-68 \mathrm{pg} / \mathrm{ml}$ \\
PTH & & \\
\hline
\end{tabular}

\section{Localization workup}

\section{MR abdomen with contrast}

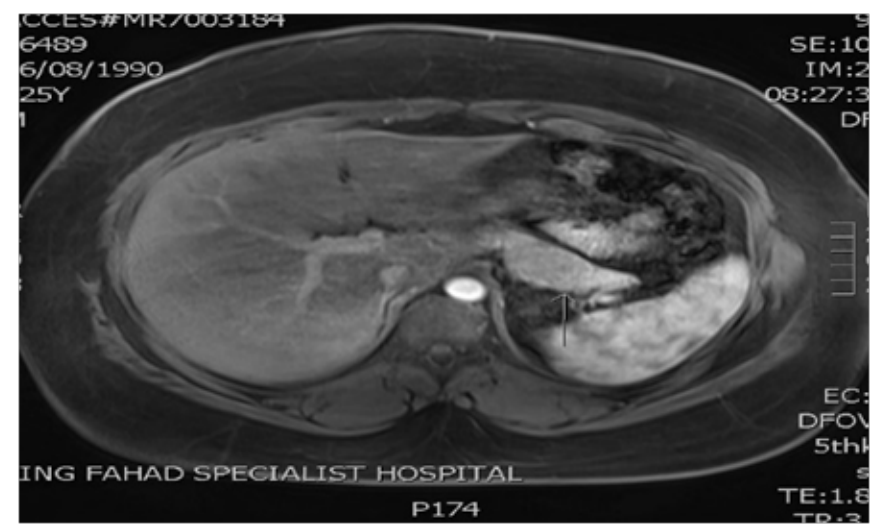

Figure 2 focal mass like lesion in the body of the pancreas with ill-defined outline $($ size $5 \mathrm{~cm} \times 3.2 \mathrm{~cm})$.

Surgery team has been consulted the patient underwent successful subtotal pancreatectomy and splenectomy. Postoperatively, blood sugar started to raise, intravenous insulin infusion initiated then shifted to subcutaneous insulin (glargine with pre-meals Aspart) for few days. After 10 days, post-surgery, the patient was discharged home with stable condition without insulin nor oral medication.

Histopathology report of pancreatic surgery was: well differentiated neuroendocrine tumor, Grade2 (Figure 3). Based on this report, Molecular genetics MEN1 gene sequencing was requested. A novel mutation was identified: heterozygous c. $1049+2 \mathrm{~T}>\mathrm{A}$ variant.

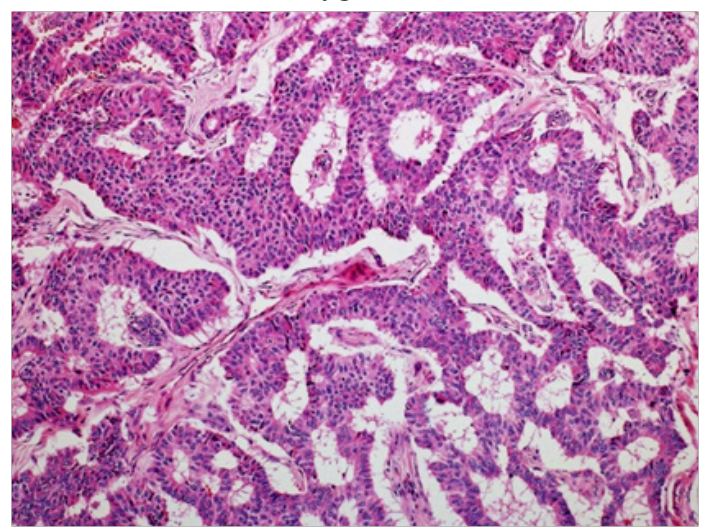

After five months from pancreatic surgery, Patient has been admitted electively after primary hyper parathyrodism localization imaging (Figure 4), to undergo total 4 glands parathyroidectomy and thymoctomy, with half parathyroid gland re implantation in the lower sternothyroid muscle, intraoperative PTH dropped from 236 to $15.5 \mathrm{pg} /$ $\mathrm{ml}$, about $90 \%$ reduction, post procedure. It was without complication. Follow up Pathology report revealed4 glands hyperplasia.

After 2 year from the patient first endocrine clinic visit, patient is in stable condition, not requiring any medical therapy or emergency room visit for endocrine cause and he lost weight of $40 \mathrm{Kg}$. We offer the patient family members genetic screening.

\section{NM parathyroid (with Sestamibi)}

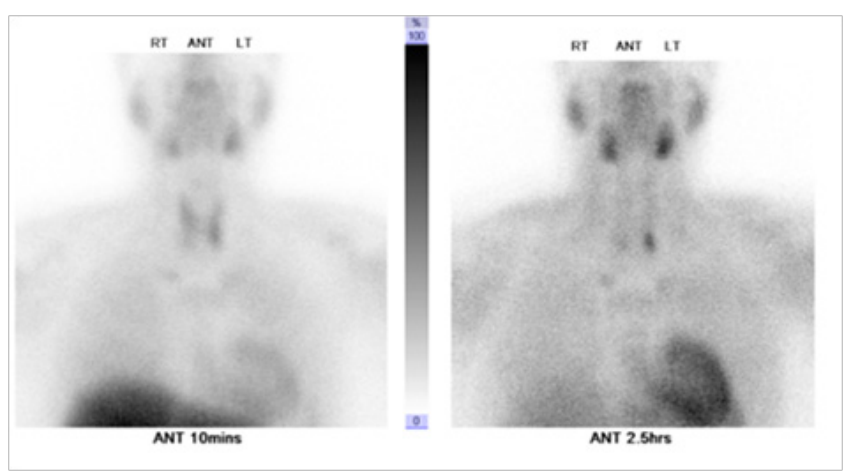

Figure 4 scintigraphic evidence suggestive of hyper functioning left lower parathyroid gland.

\section{Discussion}

The sporadic form of MEN1, where only the index person is identified in a previously unaffected family, is observed much less frequently ( $10 \%$ of cases) than the familial form ( $90 \%$ of cases), However, the distinction between sporadic and familial cases is not always easy. ${ }^{1}$

It is well accepted that the correlation between MEN1 mutation location along the gene or the type of mutation and clinical manifestations is highly difficult. ${ }^{1}$ In this reported case a new heterozygous variant c. $1049+2 \mathrm{~T}>\mathrm{A}$ affecting donor slice site of exon 8 . Based on silico analysis this new variant is most likely pathogenic.

\section{Conclusion}

This case describes a novel mutation in the MEN1 gene raises the discussion if there will ever be a genotype-phenotype association as in other MEN syndromes. ${ }^{6}$

\section{Acknowledgements}

None.

\section{Conflict of interest}

Author declares there is no conflict of interest.

\section{References}

1. Falchetti A. Genetics of multiple endocrine neoplasia type 1 syndrome: what's new and what's old. F1000Res. 2017; 24;6.

2. Trump D, Farren B, Wooding C, et al. Clinical studies of multiple endocrine neoplasia type 1 (MEN1). QJM. 1996;89(9):653-669. 
3. Namihira H, Sato M, Miyauchi A, et al. Different phenotypes of multiple endocrine neoplasia type 1 (MEN1) in monozygotic twins found in a Japanese MEN1 family with MEN1 gene mutation. Endocr J. 2000;47(1):37-43.

4. Concolino P, Rossodivita A, Carrozza C, et al. A novel MEN1 frameshift germline mutation in two Italian monozygotic twins. Clin Chem Lab Med. 2008;46(6):824-826.
5. Thakker RV, Bouloux $\mathrm{P}$, Wooding $\mathrm{C}$, et al. Association of parathyroid tumors in multiple endocrine neoplasia type 1 with loss of alleles on chromosome 11. N Engl J Med. 1989;321(4):218-224.

6. Agarwal SK. Multiple endocrine neoplasia type 1. Front Horm Res. 2013;41:1-15. 